Article

\title{
Experimental Validation of Heat Transport Modelling in Large Solar Thermal Plants
}

\author{
Kevin Sartor *(i) and Rémi Dickes \\ Thermodynamics Laboratory, University of Liège, 4000 Liège, Belgium; rdickes@ulg.ac.be \\ * Correspondence: kevin.sartor@uliege.be
}

Received: 16 April 2020; Accepted: 6 May 2020; Published: 8 May 2020

check for updates

\begin{abstract}
Solar thermal plants are often considered as a convenient and environmentally friendly way to supply heat to buildings or low temperature industrial processes. Some modelling techniques are required to assess the dynamic behaviour of solar thermal plants in order to control them correctly. This aspect is reinforced while large plants are considered. Indeed, some atmospheric conditions, such as local clouds, could have significant influence on the outlet temperature of the solar field. A common modelling approach to assess the heat transport in pipes is the one-dimensional finite volume method. However, previous work shows limitations in the assessment of the temperatures and in the computational time required for simulating large pipe networks. In this contribution, a previous alternative method developed and validated in a district heating network is used and extended to a solar thermal plant considering the thermal solar gain and the inertia of the pipes. The present contribution intends to experimentally validate this model on an existing solar plant facility available at the Plataforma Solar de Almeria in Spain.
\end{abstract}

Keywords: solar network; dynamic modelling; plug flow; control

\section{Introduction}

Solar thermal plants are one of the current solutions to change the world energy sources and to contribute to a green energy transition by recovering solar energy. The use of this kind of energy system has grown significantly for several years, especially to produce power or to supply heat to industrial processes or, in some cases, to residential buildings [1]. Moreover, among these systems, the concentration thermal plants tend to be economically competitive compared to conventional energy sources (60-100 EUR/MWh) [2], increasing their future use.

However, some modelling techniques are required to assess the dynamic behaviour of solar thermal plants to control them correctly. Indeed, like most renewable energy systems, a solar plant is facing to the intermittency of the energy source, namely the Sun, and requires some modelling techniques to couple them to other energy systems or energy storage facilities [3]. This aspect is reinforced while large plants are considered such as the solar park in Cape Town in South Africa, where the area of the solar plant can reach several $\mathrm{km}^{2}$ [4]. In this plant configuration, some atmospheric conditions, such as local clouds, could have significant influence on the outlet temperature of the solar field and a control strategy should be used to maintain the outlet plant temperature near the defined set point as a predictive control based on climatic observations [5] or with dedicated algorithms [6]. Another solution is to instrument the network at numerous key locations to measure the operating conditions (temperatures and mass flow rates). However, this method is often expensive because of the numerous expensive sensors used.

A common modelling approach to assess the heat transport in pipes is the one-dimensional finite volume method. However, previous works [7-9] show limitations in the assessment of the temperatures and in the computational time required for simulating large pipe networks. Indeed, 
the finite volume method requires a high discretisation scheme to get accurate results. However, the increasing discretisation leads to a higher computational time. This computational time could be incompatible with the control strategy.

The present contribution intends to use an existing model developed by the authors dedicated to district heating networks and to extend it to assess the dynamic behaviour of solar thermal networks. Indeed, the proposed model, based on a Lagrangian approach [10], was validated considering the working fluid as water and a reduced heat transfer between the pipes and the ambient due to the large insulation of the pipes. In this contribution, the working fluid considered is oil and the heat transfer is higher due to the thermal power recovered from the Sun. Therefore, the model is extended into solar thermal plants, considering the thermal solar gain and the inertia of the piping system. The case study used to validate the dynamic model is a parabolic trough collectors (PTC)-based solar plant facility installed at the Plataforma Solar de Almeria in Spain.

The developed model allows for a further study to investigate control strategy definitions and their optimisation. Although this paper focuses on the experimental validation of a medium-size solar thermal plant, it could be extended to the modelling of larger solar plants, while the key element behaviour, namely a pipe, is studied and validated.

\section{Problem Statement}

A typical solar thermal plant is composed of a piping system dedicated to transport the energy recovered from the Sun to a defined process. In large solar thermal plants, the total pipe network length can reach over several kilometres. Therefore, the heat propagation through the network depends on the fluid velocity, which can induce some delay. These delays could reach some minutes or even hours, depending of the operating conditions and the pipe length. Indeed, the order of magnitude of the working fluid velocity is generally some meters per second to limit the pressures losses and the related electric pump consumption and it depends on the control strategies of the plant.

Previous works of the authors $[7,11]$ show that a one-dimensional finite-volume method is able to model the dynamic behaviour of this kind of network. However, this modelling method requires an important spatial discretisation of the pipe to get accurate results. This spatial discretisation leads to high computational time requirements, which is not compatible with the final purpose of the modelling, i.e., the investigation and the optimisation of control strategies. For lower spatial discretisation layouts, a phenomenon named "numerical diffusion" occurs $[7,8,12]$ and reduces the accuracy of the finite volume method by anticipating the heat waves at the pipe outlet.

Therefore, it is proposed to counter these issues by considering an alternative modelling method called the "plug flow" method, which is briefly detailed in the following section. The plug flow method accuracy is of the same order of magnitude as the one of the finite-volume method, with important spatial discretisation. Moreover, the simulation speed of the plug flow method is improved and is clearly one advantage for the definition and the optimisation of control strategies, such as model-based predictive control methods. Indeed, in large thermal networks, the weather conditions, and more specifically, the solar irradiance, can have an important influence on the performance of some parts of the plant, especially if a given outlet temperature is required for the supplying process connected to the solar thermal plant.

The plug flow modelling method has already been validated experimentally on a district heating network. However, such a district heating network involves a very low heat transfer between the pipe and the ambient due to the high insulation used on the piping system. In order to go a step further, this contribution proposes to experimentally validate the "plug flow" method on a solar thermal network facility characterised by a very high transfer. More specifically, the plug flow model is used to simulate a field of PTC, as described in Section 4. 


\section{Modelling}

Regarding the flow inside the pipe, the proposed modelling method is derived on the standard TRNSYS Type 31 component. This modelling method is based on a Lagrangian approach, i.e., the properties of each fluid particle are considered along with their direction in function of time, considering the energy balance [10]. In order to simplify the resolution of the whole system, the flow is considered as incompressible, which is valid if the fluid is a liquid and for low pressure variations [13]. Moreover, the wall friction dissipation and the energy coming from the pressure drop into the pipe are neglected as the axial diffusion. This method was previously analysed, developed and validated under the Matlab platform for different operating conditions and pipe layouts [7,14], but has now been successfully ported to Modelica language [11] and the related open-source Modelica library is available in [15].

The current model is based on a simplified combination of energy and continuity equation (Equation (1)) [11]:

$$
\frac{\partial\left(\rho c_{p} A T\right)}{\partial t}+\frac{\partial\left(\rho c_{p} A v T\right)}{\partial x}=-\dot{q}_{e}
$$

where $\rho$ denotes the density, $c_{p}$ is the fluid specific heat, $A$ is the pipe cross section $\left(\mathrm{m}^{2}\right), v$ is the flow velocity, $x$ is the spatial coordinate, $t$ is the time, $T$ is the temperature and $\dot{q}_{e}$ is the heat loss per unit length (which is positive for heat loss from pipe to the ground).

Considering in the Lagrangian approach that the observer is attached to a fluid parcel, there is no notion of spatial coordinate. Finally, after rearranging the previous equation, it is possible determine the outlet pipe temperature $\left(T_{\text {outlet }}\right)$ through the Equation (2):

$$
T_{\text {outlet }}=T_{\text {ground }}+\left(T_{\text {inlet }}-T_{\text {ground }}\right) \cdot \exp \left(-\frac{\Delta T}{R C}\right),
$$

$\Delta T$ is the delay time of the fluid parcel travelling the pipe; $R$ is the thermal resistance between the fluid temperature and the ground temperature, which can be calculated by [16] or [17] depending on the geometric characteristics of the pipe, and $C$ is the heat capacity per unit length of the water into the pipe. In this case, the fluid temperature is assumed uniform throughout the cross section of the pipe.

In the Modelica modelling, a unique volume is considered for the pipe. To assess the time delay of a fluid parcel between the inlet and the outlet of a pipe, the following dynamic equation (Equation (3)) is solved:

$$
\frac{\partial z(y, t)}{\partial t}+v(t) \frac{\partial z(y, t)}{\partial y}=0
$$

where $z(y, t)$ is the transported quantity, $y$ is the normalised spatial coordinate, $t$ is the time and $v(t)$ the normalised velocity. An approximation of the one-way wave equation was successfully introduced with the spatialDistribution() operator defined in the Modelica Language Specification [18]. This modelling method considers the heat propagation, the thermal inertia of the piping system, the pressure losses and the heat transfer with the ambient.

The hydraulic behaviour is assessed by a previously developed model denoted HydraulicDiameter of the Annex 60 Library [15]. In this case, the pressure drop $(\Delta P)$ is coupled to the mass flow rate (m) using a quadratic relation as in (4):

$$
\dot{m}=k \sqrt{\Delta P},
$$

where $\mathrm{k}$ is a constant depending on the piping system in function of the nominal conditions (nominal pressure losses for a nominal mass flow rate). A thermal capacity is added to the core pipe model at the outlet of the pipe to account for the thermal inertia of the pipe constituting material as [19]. The interested reader could refer to [11] for further details.

Regarding the heat transfer to the pipe, the radial heat balance between all the heat collection element components (see Figure 1) is modelled according to the deterministic model proposed by Forristal [20], which accounts for the most important phenomena, i.e.,: 
- conduction and thermal energy accumulation in the metal pipe;

- convection and radiation between the glass envelope and the metal pipe;

- conduction and thermal energy accumulation in the glass envelope;

- radiation and convection losses to the environment.

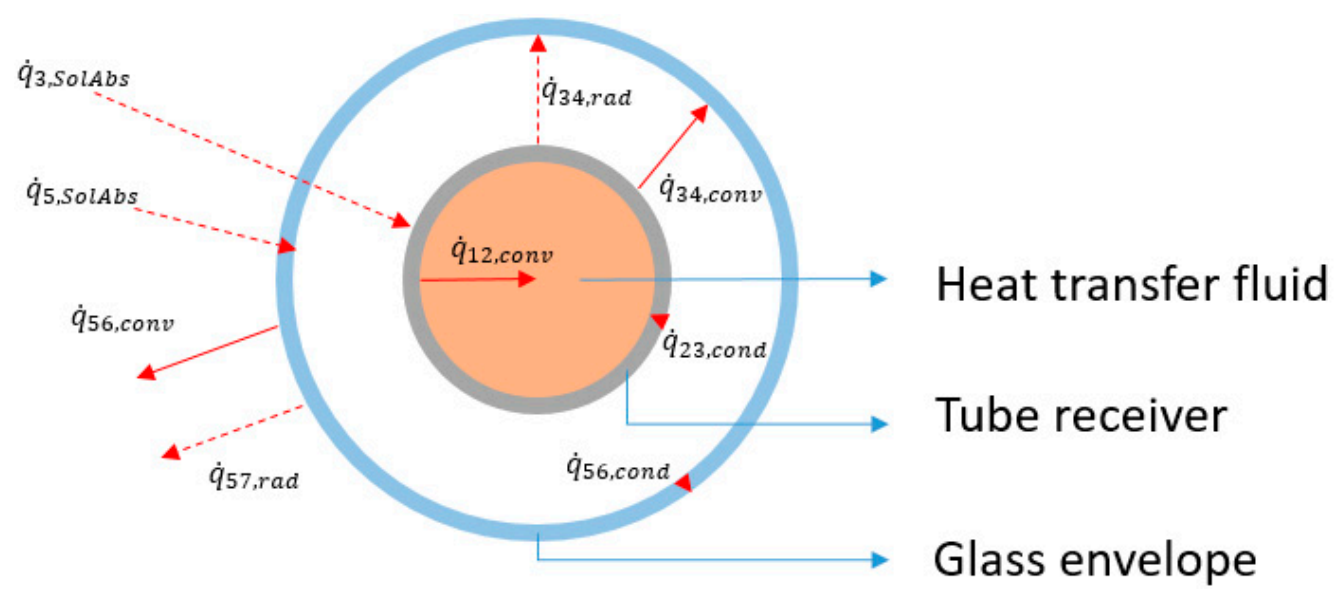

Figure 1. Energy balance around the heat collection element. In blue, the glass envelope; in grey, the metal pipe; and in white, the vacuum between the two. Heat transfer is highlighted with red arrows. Based on [21].

It is assumed that temperatures, heat transfer coefficients and thermodynamic properties are considered uniform around the circumference of the heat collector. Moreover, thermal losses through the support brackets are neglected and solar absorption in the tube and the glass envelope is treated as a linear phenomenon [21]. For further information about the original model, the reader can refer to [21-23].

For larger network where several pipes are interconnected, energy, mass and momentum balances could be performed on the key location to assess the energy and mass repartition inside the whole system according to [18].

\section{Experimental Apparatus}

The reference data used for the model validation are experimental measurements gathered on the Parabolic Trough Test Loop (PTTL) facility installed at the Plataforma Solar de Almería in Spain [24]. The data are recovered from a previous work presenting a finite-volume dynamic model of parabolic trough collectors [21]. As depicted in Figure 2, the facility includes three parallel lines of PTC from different manufacturers (AlbiasaTrough, EuroTrough and UrssaTrough) but only the EuroTrough collectors (ETC) are used in this work. The ETC line is composed of 6 EuroTrough modules connected in series and 18 prototype receiver tubes from a Chinese manufacturer, for a total length of $70.8 \mathrm{~m}$ and a net aperture area of $409.9 \mathrm{~m}^{2}$. The system is a closed loop, with an East-West orientation and it is charged with the thermal oil Syltherm 800 [25].

The system operation is quite straightforward. A centrifugal pump drives the fluid from the point (1) through one of the three parallel PTC lines of the solar field. In the collectors (i.e., from points (2) to (3)), the heat transfer fluid is heated by absorbing solar energy reflected by the collectors onto the receiver tubes. The fluid is then cooled down by two air-cooled heat exchangers characterised by a maximum thermal capacity of $400 \mathrm{kWth}$. A $1 \mathrm{~m}^{3}$ expansion vessel (filled by nitrogen) is placed in between the two air coolers to regulate the loop pressure (18 bar max). Finally, two additional electric heaters are installed at the outlet of the pump to control the oil temperature at the PTC inlet port.

The temperatures at the inlet and at the outlet of the PTC are measured with temperature transmittance sensors (denoted $\mathrm{T}$ in Figure 2). The direct normal irradiation (DNI) is measured with a 
pyrheliometer model $\mathrm{CH} 1$ by Kipp\&Zonen [26]. A weather station installed nearby the solar field is used to measure the ambient conditions (temperature, humidity, wind speed and direction). The data acquisition system is based on National Instrument devices with a sampling time of 5 seconds. LabView software is used for data visualisation. The mass flow rate is derived from a data calibration study performed on the pump to assess it in function of the working conditions.

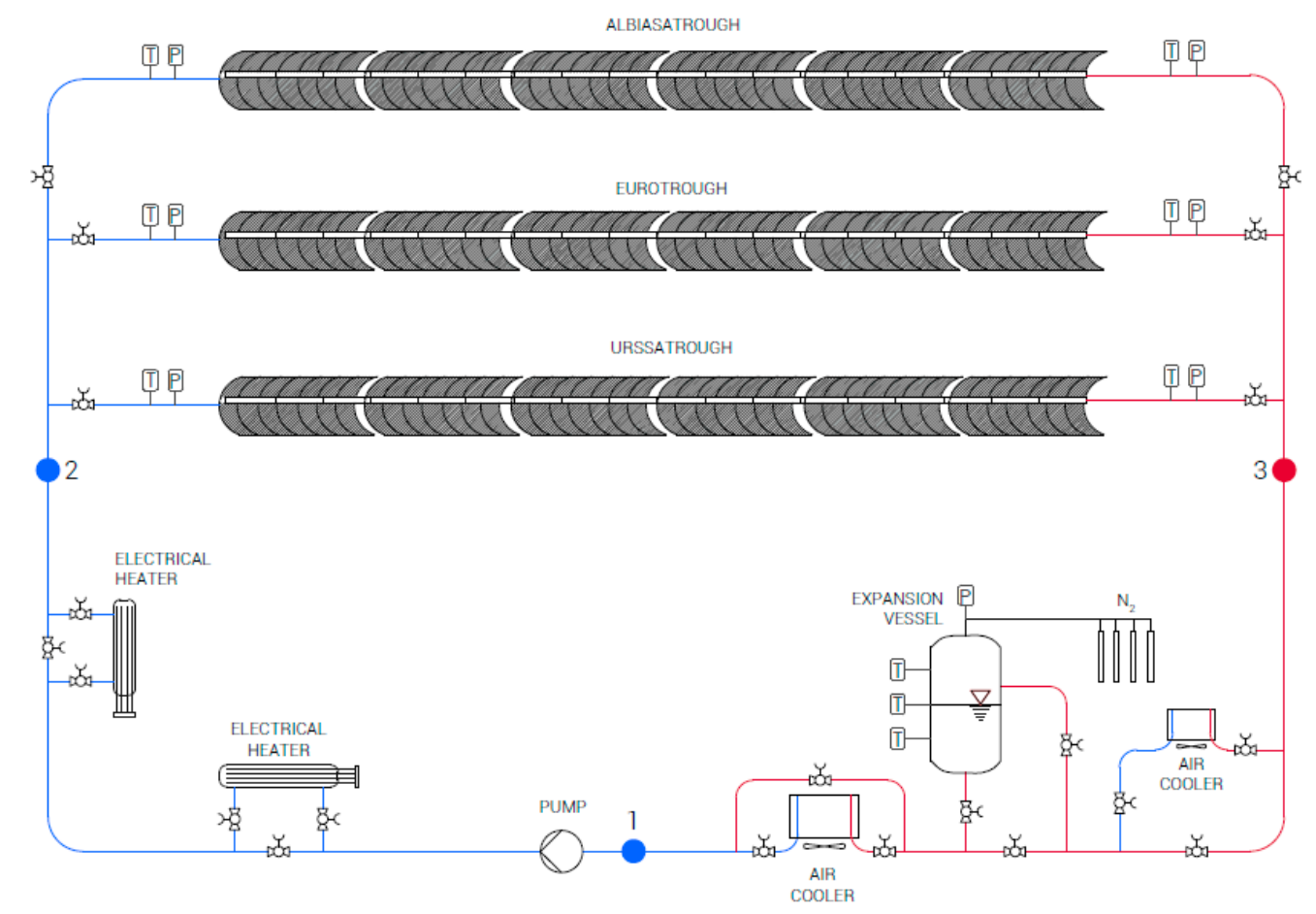

Figure 2. Process flow diagram of the Parabolic Trough Test Loop (PTTL) facilities with the relative sensors and devices position [21].

In Table 1, the working conditions of the main variables and of the external ambient parameters during the experimental campaign are reported.

Table 1. Range of the operation of the EuroTrough collectors (ETC) main variable and of the external ambient condition during the experimental campaign.

\begin{tabular}{ccccccc}
\hline Variable & $\dot{m}$ & $T_{\boldsymbol{s u}}$ & $\boldsymbol{T}_{\boldsymbol{e x}}$ & $\boldsymbol{D N I}$ & $\boldsymbol{T}_{\boldsymbol{a} \boldsymbol{m} \boldsymbol{b}}$ & $\boldsymbol{v}_{\text {wind }}$ \\
\hline Unit & $\mathrm{kg} / \mathrm{s}$ & ${ }^{\circ} \mathrm{C}$ & ${ }^{\circ} \mathrm{C}$ & $\mathrm{W} / \mathrm{m}^{2}$ & ${ }^{\circ} \mathrm{C}$ & $\mathrm{m} / \mathrm{s}$ \\
\hline Min & 1.55 & 150.05 & 170.21 & 593.95 & 26.23 & 0 \\
Max & 5.03 & 304.48 & 352.28 & 883.72 & 33.16 & 11.23 \\
\hline
\end{tabular}

In order to perform the dynamic validation of the modelling method, three different scenarios are tested on the system:

- Oil mass flow change experiment (MFE): a step change is imposed onto the oil mass flow rate at the inlet of the ETC by varying the pump speed upwards or downwards, starting from a steady-state condition.

- Oil inlet temperature change experiment (TE): the oil temperature at the inlet of the ETC is varied by shutting down the air cooler, starting from a steady-state condition.

- Solar beam radiation change experiment (SBE): a step change to the solar beam radiation collected on the receiver is imposed downwards and upwards to the parabolic trough collectors by defocusing and focusing the parabolic trough collectors. 


\section{Results and Discussion}

In this section, the model presented in Section 3 is validated onto the data presented in Section 4. The simulation is performed under Dymola2017 using Modelica language and the Differential Algebraic System Solver [27] with a relative tolerance of $10^{-4}$. The results of [21], obtained with the one-volume finite modelling, are also used to compare the accuracy of the current model with this other common modelling method.

A good agreement is found between the experimental data and the modelling results as it can be seen in the figures available into this section. In Figure $3 a, b$, only TE and MFE scenarios are considered. When the mass flow rate increases (resp. decreases), the outlet pipe temperature decreases (resp. increases) a few times after, due to the quasi-constant energy transmitted to the pipe (during this experiment the DNI is quite constant). On the other hand, a heat wave propagation induced by an increase of the inlet temperature is also correctly modelled, while the trend of the outlet pipe temperature follows the experimental data.

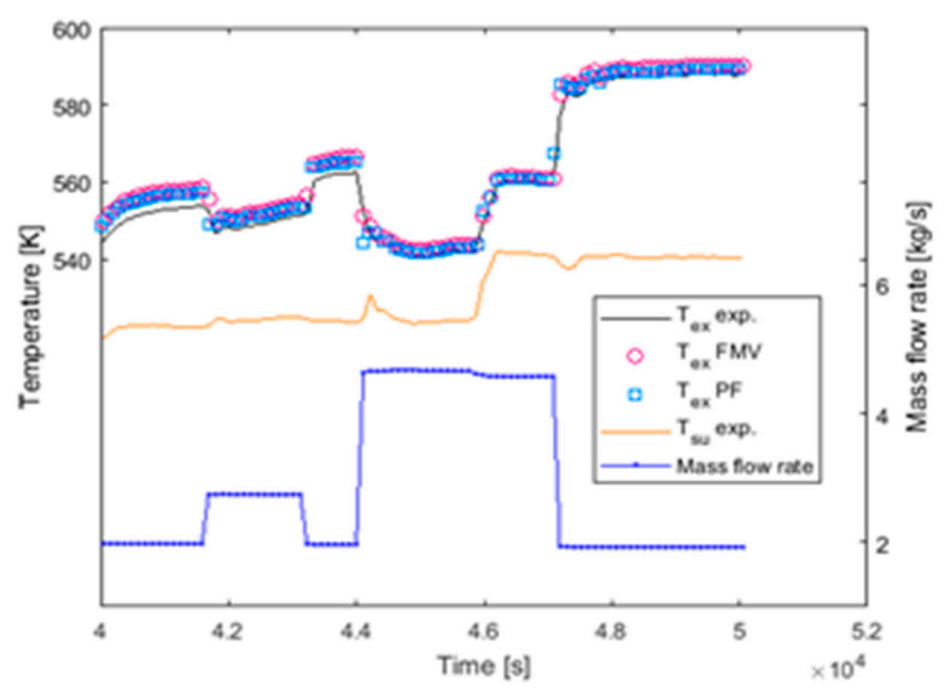

(a)

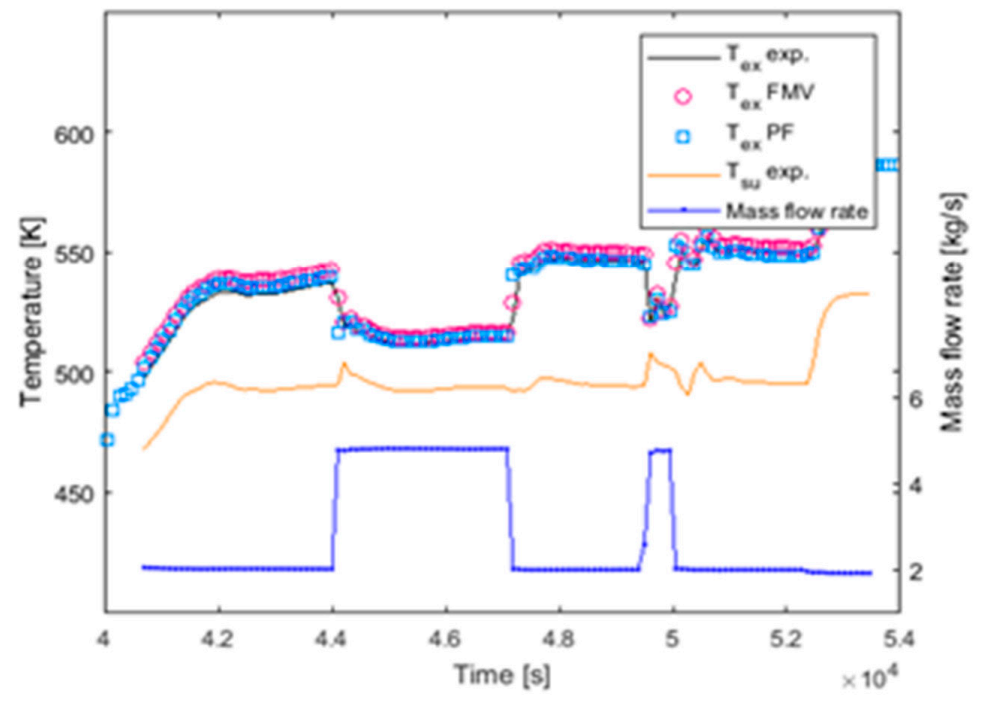

(b)

Figure 3. Experimental results performing different days versus plug flow and finite volume methods for several inlet temperature and mass flow rate conditions. (a) Test conditions \#1; (b) Test conditions \#2. 
For the sake of clarity, in Figure $4 a, b$, only the SBE steps are noted on the experimental trends (denoted SBE) while TE and MFE conditions can be deduced from the figures. These SBE conditions are used to determine the influence of a cloud passing over the PTC system.

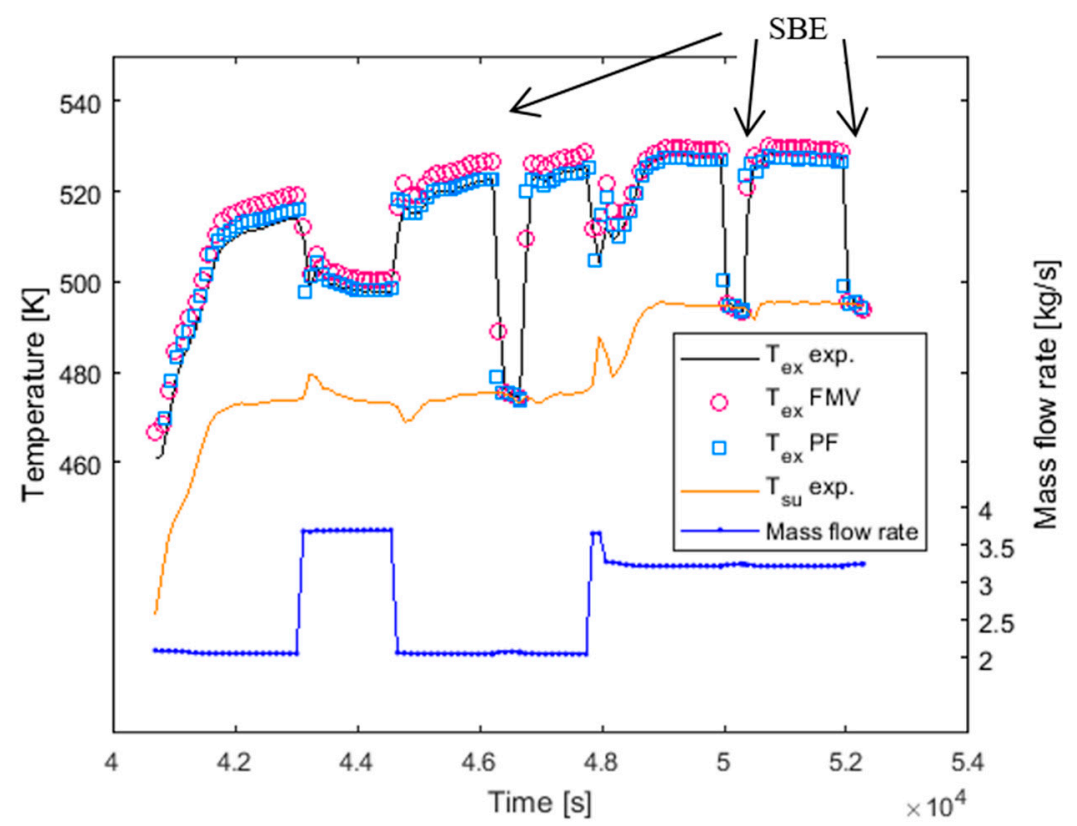

(a)

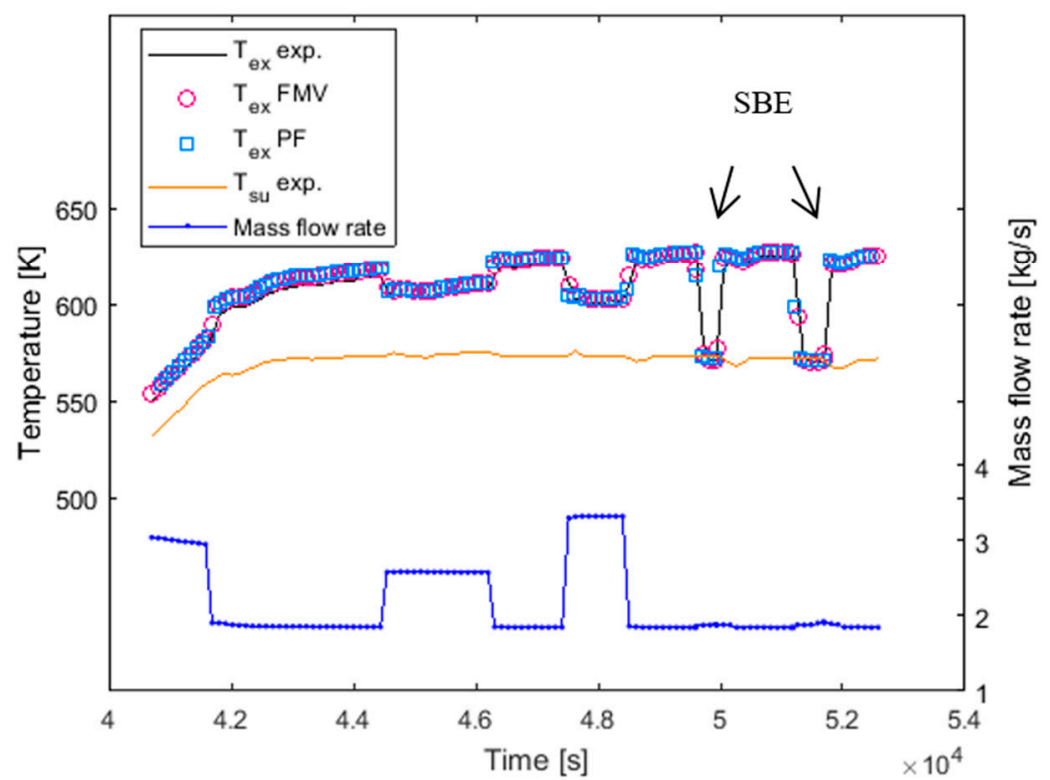

(b)

Figure 4. Experimental results performing different days versus plug flow and finite volume methods for several inlet temperature, mass flow rate and solar beam conditions. (a) Test conditions \#3; (b) Test conditions \#4.

Once again, the evolution of the predicted outlet temperature follows the experimental trends for several mass flow steps, inlet temperature steps and solar energy steps or a combination of them (Figure 4).

In all the cases studied, the accuracy is of the same order of magnitude as the finite volume method, with a discretisation of 50 cells which is the reference case of the study [21]. 
While the aim of this study is to consider active control strategies, the last experiment is presented in Figure 5 to assess the dynamic behaviour of the system when combinations of operating conditions steps are considered. Once again, there is a good agreement between plug flow modelling and the experimental data for wide variations of the mass flow rate, inlet pipe temperature and solar beam.

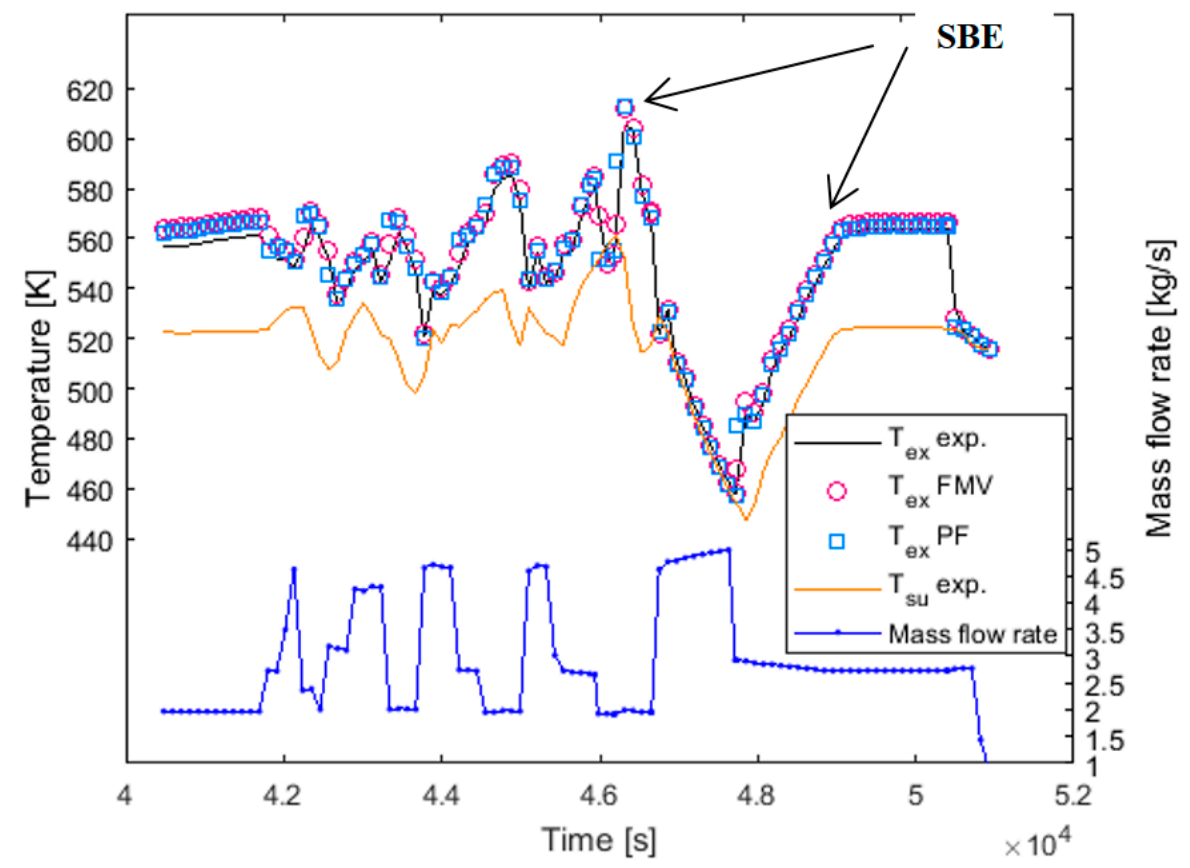

Figure 5. Experimental results performing one day versus plug flow and finite volume methods for a combination of inlet temperature, mass flow rate and solar beam step conditions.

As shown in previous study of district heating network modelling, the thermal inertia of the system and the operating mass flow rate have a significant influence on the outlet temperature response. Indeed, the mass flow rate influences how the fluid is propagated into the pipe, while the influence of thermal inertia can be seen when SBE conditions are set and can lead to significant extra delay (over $200 \mathrm{~s}$ ) to get an outlet temperature with a similar value as the inlet temperature (considering the heat transfer to the ambient constant).

In this contribution, the simulation time required to model the process with plug flow modelling is generally reduced from a factor 20 to 30 compared to the finite volume method. This variation depends on the operating conditions and their trends. While this factor could seem quite reduced, it can be increased drastically in a larger network due to the higher complexity of the general problem. Indeed, in large networks with some intersections between the pipes, the hydraulic part of the problem can become complex to solve due to quadratic law relationship between pressure losses and the mass flow rates.

\section{Conclusions}

Solar thermal networks take place in the world energetic transition to supply clean thermal energy to process or residential needs. To optimise them and develop dedicated control strategies, it is required to assess the state of the heat transfer fluid correctly in several key points of the network, depending on the operating conditions. A practical solution could be to instrument these plants, but this solution is generally expensive and is not always easy to implement due to technical constraints. A second solution consists of modelling the dynamic behaviour of the whole system based on few input data.

In this contribution, the use of a previously developed plug flow approach for the district heating network modelling is extended through an experimental validation on a solar thermal network test bench. This validation step is required to check the assessment of the dynamic behaviour of the plant. 
Indeed, the main difference between district heating networks and thermal networks is the magnitude of heat transfer between the piping system and the ambient. This experimental validation considers inlet temperature and mass flow rate variations, as it could be happening in some control strategies. On the other hand, the weather influence is simulated by a modified solar energy recovered to the pipes through a modified and controlled focussing and defocussing of the PTC system.

All the results show a good agreement between experimental data and simulation results for a wide range of operating conditions of the thermal plant. Moreover, the accuracy of the model is similar to those of the one-dimensional finite volume method with a reduced simulation time by a minimal factor of 20.

The next step of this work will consist of the definition and the optimisation of dedicated control strategies of the thermal plant to ensure the best control of the temperature required by the energy process.

Author Contributions: Conceptualization, K.S.; methodology, K.S.; software, K.S. and R.D.; validation, K.S.; formal analysis, K.S.; investigation, K.S.; resources, K.S. and R.D.; data curation, K.S. and R.D.; writing—original draft preparation, K.S.; writing —-review and editing, K.S.; visualization, K.S. and R.D.; supervision, K.S.; project administration, K.S. and R.D. All authors have read and agreed to the published version of the manuscript.

Funding: This research received no external funding.

Conflicts of Interest: The authors declare no conflict of interest.

\section{Nomenclature}

$\dot{m} \quad$ Mass flow rate, $\mathrm{kg} / \mathrm{s}$

$\dot{q}_{e} \quad$ Heat loss per unit length W/m

$c_{p} \quad$ Specific heat capacity, $\mathrm{J} / \mathrm{kg}^{\circ} \mathrm{C}$

$\rho$ Density, $\mathrm{kg} / \mathrm{m}^{3}$

A Pipe cross section, $\mathrm{m}^{2}$

DNI Direct normal irradiation $\mathrm{W} / \mathrm{m}^{2}$

FMV Finite Volume Method

HTF Heat transfer fluid

MFE mass flow change experiment

P Pressure, bar

PF Plug Flow

PTC Parabolic Trough Collector

PTTL Parabolic Trough Test Loop

SBE Solar beam radiation change experiment

$\mathrm{T}$ temperature, ${ }^{\circ} \mathrm{C}$

TE inlet temperature change experiment

$\mathrm{t}$ time, $\mathrm{s}$

v velocity, $\mathrm{m} / \mathrm{s}$

$\mathrm{x}$ spatial coordinate

y normalised spatial coordinate

Subscripts and superscripts

amb ambient

conv convective (heat transfer)

ex exhaust

rad radiative (heat transfer)

SolAbs Solar power absorbed

su supply 


\section{References}

1. Duffie, J.A.A.; Beckman, W.A. Solar Engineering of Thermal Processes; John Wiley \& Sons, Inc.: Hoboken, NJ, USA, 2013.

2. Andrei, I.; Ralon, P.; Rodriguez, A.; Taylor, M.; International Renewable Energy Agency. Abu Habi: 2017. Available online: https://www.irena.org/-/media/Files/IRENA/Agency/Publication/2018/Jan/IRENA_2017_ Power_Costs_2018.pdf (accessed on 7 April 2020).

3. Pramanik, S.; Ravikrishna, R.V. A review of concentrated solar power hybrid technologies. Appl. Therm. Eng. 2017, 127, 602-637. [CrossRef]

4. Mathews, J.A.; Hu, M.-C.; Wu, C.-Y. Concentrating solar power: A renewable energy frontier. Carbon Manag. 2014, 5, 293-308. [CrossRef]

5. Martínez, D.; Rubio, F.R.; Berenguel, M.; Camacho, E.F. Control of Solar Energy Systems; Springer-Verlag: London, UK, 2012. [CrossRef]

6. Schlipf, D.; Schneider, G.; Maier, H. Using evolutionary algorithm to develop a feed forward control for CSP plant using mid- and long term storages. Energy Procedia 2013, 49, 2191-2200. [CrossRef]

7. Sartor, K.; Thomas, D.; Dewallef, P. A comparative study for simulating heat transport in large district heating networks. Int. J. Heat Technol. 2018, 36, 301-308. [CrossRef]

8. Van den Bossche, G. Lokale Temperatuurverhoging Versus Tijdmodulatie in Lage Temperatuur Warmtenetten. Ph.D. Thesis, KULeuven, Leuven, Belgium, 2015.

9. Grosswindhager, S.; Voigt, A.; Kozek, M. Linear finite-difference schemes for energy transport in district heating networks. In Proceedings of the 2nd International Conference on Computer Modeling and Simulation, Brno, Czech Republic, 5-7 September 2011; pp. 5-7.

10. Bennett, A. Lagrangian Fluid Dynamics; Cambridge University Press: Cambridge, UK, 2006.

11. van der Heijde, B.; Fuchs, M.; Tugores, C.R.; Schweiger, G.; Sartor, K.; Basciotti, D.; Müller, D.; Nytsch-Geusen, C.; Wetter, M.; Helsen, L. Dynamic equation-based thermo-hydraulic pipe model for district heating and cooling systems. Energy Convers. Manag. 2017, 151, 158-169. [CrossRef]

12. Sartor, K. Annex 60: Subtask 2.2 Modeling Heat Transport in District Heating Networks; Annex 60: Paris, France, 2015.

13. Hoffman, J.; Johnson, C. Computational Turbulent Incompressible Flow; Springer: Berlin/Heidelberg, Germany, 2007; Volume 4. [CrossRef]

14. Sartor, K.; Dewalef, P. Experimental validation of heat transport modelling in district heating network. Energy 2017, 137, 961-968. [CrossRef]

15. Wetter, M.; Fuchs, M.; Grozman, P.; Helsen, L.; Jorissen, F.; Lauster, M. IEA EBC ANNEX 60 Modelica library-An international collaboration to develop a free opensource model library for buildings and community energy systems. In Proceedings of the BS2015 14th International Building Performance Simulation Association, Rome, Italy, 2-4 September 2019; pp. 395-402.

16. Bøhm, B. On transient heat losses from buried district heating pipes. Int. J. Energy Res. 2000, 24, 1311-1334. [CrossRef]

17. Velut, S.; Tummescheit, H. Implementation of a transmission line model for fast simulation of fluid flow dynamics. In Proceedings of the 8th International Modelica Conference, Dresden, Germany, 20-22 March 2011; p. 8 .

18. Association, M. Modelica $(-A$ Unified Object-Oriented Language for Systems Modeling Language Specification. 2014. Available online: https://www.modelica.org/documents/ModelicaSpec33Revision1.pdf (accessed on 7 May 2020).

19. Benonysson, A.; Bøhm, B.; Ravn, H.F. Operational optimization in a district heating system. Energy Convers. Manag. 1995, 36, 297-314. [CrossRef]

20. National Renewable Energy Laboratory. Heat Transfer Analysis and Modeling of a Parabolic Trough Solar Receiver Implemented in Engineering Equation Solver; National Renewable Energy Laboratory: Golden, CO, USA, 2003.

21. Desideri, A.; Dickes, R.; Bonillab, J.; Valenzuela, L.; Quoilin, S.; Lemort, V. Steady-state and dynamic validation of a parabolic through collector model using the ThermoCycle Modelica library. Sol. Energy 2018, 174, 866-877. [CrossRef]

22. Dahm, J. District Heating Pipelines in the Ground-Simulation Model. 2001. Available online: https: //trnsys.de/download/de/ts_type_313_de.pdf (accessed on 26 September 2016). 
23. TRNSYS 17 Manual-Volume 4-Mathematical Reference 2009, 486. Available online: https://docplayer. net/13373943-Trnsys-17-volume-4-mathematical-reference-a-transient-system-s-imulation-program.html (accessed on 23 December 2018).

24. León, J.; Clavero, J.; Valenzuela, L.; Zarza, E.; García, G. PTTL-A Life-size Test Loop for Parabolic Trough Collectors. In Proceedings of the SolarPACES 2013 International Conference, Las Vegas, NV, USA, 17-20 September 2013; Volume 49, pp. 136-144. [CrossRef]

25. Dow Inc. Syltherm 800 Heat Transfer Liquid; Dow Inc.: Midland, MI, USA, 1997.

26. Kipp \& Zonen B.V. CH1 Normal Incidence Pyrhelimeter Manual; Kipp \& Zonen B.V.: Delft, The Netherlands, 1997.

27. Petzold, L.R. A Description of DASSL: A Differential-algebraic system solver. In Proceedings of the 10th IMACS World Congress, Montreal, QC, Canada, 8-13 August 1982; pp. 65-68.

C 2020 by the authors. Licensee MDPI, Basel, Switzerland. This article is an open access article distributed under the terms and conditions of the Creative Commons Attribution (CC BY) license (http://creativecommons.org/licenses/by/4.0/). 